\title{
Homicide* and Suicide ${ }^{\dagger}$ Death Rates ${ }^{\S}$ for Persons Aged 15-19 Years - National Vital Statistics System, United States, 1999-2016
}

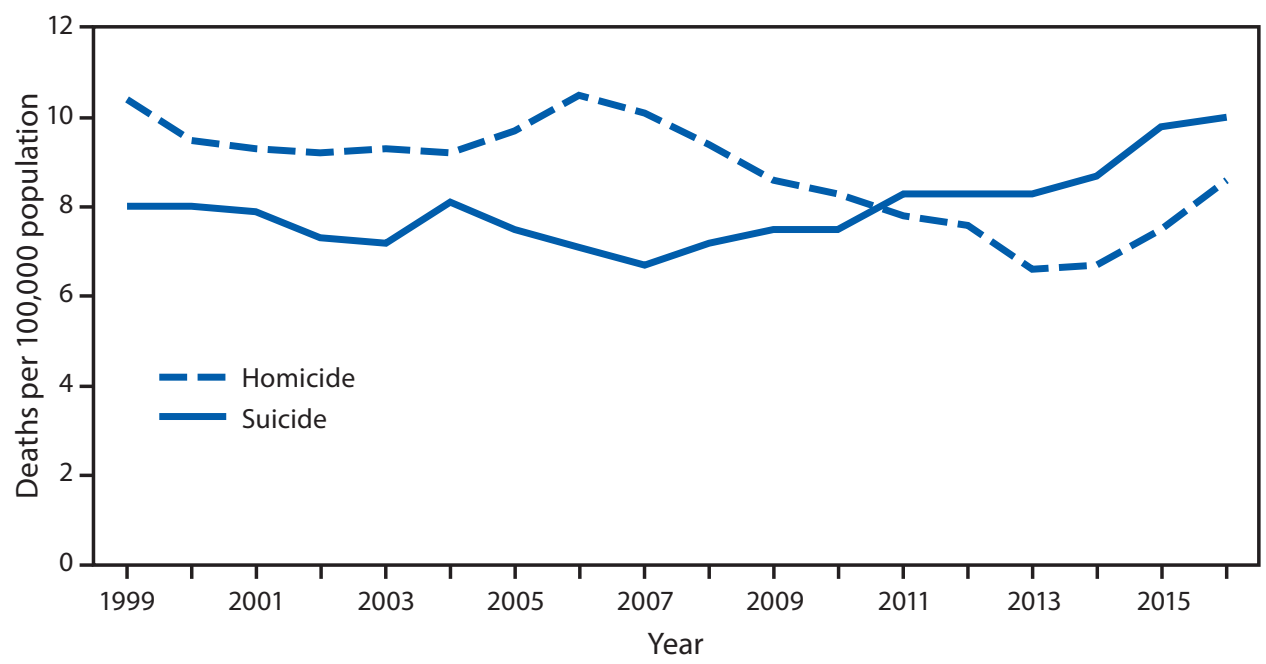

* Homicides are identified with International Classification of Diseases, Tenth Revision codes X85-Y09, Y87.1, and U01-U02. In 2016, there were 1,816 homicides among persons aged 15-19 years.

† Suicides are identified with International Classification of Diseases, Tenth Revision codes X85-Y09, Y87.1, and U03. In 2016, there were 2,117 suicides among persons aged 15-19 years.

$\S$ Rates are per 100,000 population aged 15-19 years.

In 1999, the homicide death rate for persons aged 15-19 years (10.4 per 100,000) was higher than the suicide rate (8.0). By 2010-2011, the homicide and suicide rates had converged. After 2011, the suicide rate increased to 10.0 in 2016; the homicide rate declined through 2013 but then increased to 8.6 in 2016.

Source: National Vital Statistics System. 1999-2016. https://www.cdc.gov/nchs/nvss/deaths.htm.

Reported by: Sally C. Curtin, MA, scurtin@cdc.gov, 301-458-4142; Arialdi M. Minino, MPH.

For more information on this topic, CDC recommends the following link: https://www.cdc.gov/violenceprevention/index.html. 